\title{
EXPERIENCIA ESTÉTICA Y DESARROLLO SOSTENIBLE: UN ESTUDIO DE CASO
}

\author{
Thiago Pinto Barbosa, Manuel Rivera, Francisca Mena Vergara, Mariela Paredes Reinoso y \\ Milena Morales Bonich ${ }^{1}$
}

\section{Resumen/Abstract}

A partir de la pregunta de cómo pueden contribuir las artes para la comunicación sobre desarrollo sostenible, el estudio hace un análisis sociológico-antropológico de la recepción de una exposición internacional de arte contemporáneo sobre sostenibilidad en Valparaíso, Chile. La experiencia estética del público comprueba que el arte, a través de componentes sensuales y estrategias estéticas que conducen a la reflexión, puede fertilizar la susceptibilidad a cuestiones de desarrollo sostenible. Esa potencialidad es capaz de identificar lagunas en la discusión pública local sobre sostenibilidad, pero no es capaz de rellenarlas.

Palabras clave: experiencia estética, sostenibilidad, arte contemporáneo, Valparaíso

\section{AESTHETIC EXPERIENCE AND SUSTAINABLE DEVELOPMENT: A CASE STUDY}

Motivated by the question of how the arts can contribute to communication on sustainable development, this study makes a sociological-anthropological analysis of the reception of an international contemporary art exhibition on sustainability in Valparaíso, Chile. The public's aesthetic experience demonstrates that art, through sensual components and aesthetic strategies that lead to reflection can advance susceptibility to questions of sustainable development. This potential can point to gaps in the local public discussion on sustainability, but it is not capable of filling them.

Keywords: aesthetic experience, sustainability, contemporary art, Valparaíso

\footnotetext{
${ }^{1}$ Los y las autores son, respectivamente, brasileño-alemán, alemán-chileno y chilenas; los dos primeros son investigadores del Institute for Advanced Sustainability Studies (IASS Potsdam, Alemania) con formación en ciencias sociales, y las tres últimas son sociólogas de la Universidad de Valparaíso. E-mail: thbarbosa@gmail.com, manuel.rivera@iass-potsdam.de, franciscamv@gmail.com,m.paredesreinoso@gmail.com y milenamorales1@gmail.com.
} 


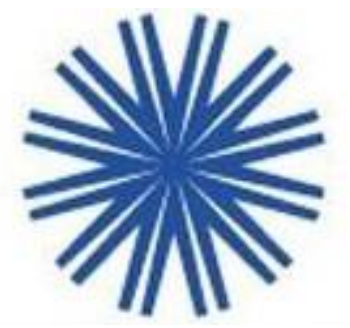

\section{Introducción}

Siendo signatario de la Agenda 2030 para el Desarrollo Sostenible (DS) de la ONU y uno de los países más afectados por el cambio climático global, Chile enfrenta graves problemas socioambientales a lo largo de todo su territorio. Sin embargo, esos problemas no se reflejan en una amplia discusión y comunicación sobre la sostenibilidad. Es probable que esta carencia se vea al menos reforzada por el desafío que presenta la estructura demográfica-espacial del país: al igual que otros países sudamericanos como Argentina y Venezuela, Chile no sólo presenta una de las más altas tazas de urbanización del mundo, ${ }^{2}$ sino también tiene casi la mitad de su población total concentrada en la región metropolitana de Santiago, es decir en un área que equivale a apenas $2 \%$ de su superficie nacional total. ${ }^{3}$ De esa forma, los estragos causados por la minería, el derretimiento de glaciares en el lejano sur, la contaminación del mar por la pesquería industrial y acuicultura, o los conflictos por tierra y agua en torno a actividades agroindustriales suenan distantes o permanecen invisibles en la experiencia diaria de grandes partes de la población chilena.

La dificultad de visibilizar los problemas ecológicos de gran escala presenta un reto central a los actores comprometidos con la sostenibilidad. La comunicación en contextos urbanos a menudo está marcada por brechas entre un saber ambiental mediatizado y un actuar cotidiano para el cual ese saber parece irrelevante, entre una (cons)ciencia abstracta sobre la problemática global y el predominio fácticocognitivo de constreñimientos locales. En reflexiones desde las ciencias se ha dado una continua discusión sobre cómo abordar el problema de la insostenibilidad estructural. Por un lado, se enfatiza la necesidad de transgredir las fronteras disciplinarias para abordar el reto del DS en su complejidad, con sus enmarañadas relaciones causa-efecto que atraviesan por distintos lugares, tiempos y seres, conectándolos (Tsing, 2015). Por otro, se discuten los límites del impacto que pueda tener la comunicación científico-argumentativa. Dado que narrativas, en la comunicación pública, parecen tener tanta o más importancia que los hechos ordenados por ellas, las indagaciones sobre el uso de narraciones, metáforas e imágenes en la comunicación pública cobran renovada importancia (Green y Brock, 2000). En este artículo, deseamos

\footnotetext{
2 89,5\% en 2015 (Moreno, Clos y Ki-moon, 2016:. 200).

${ }^{3}$ Ver http://www.subdere.cl
} 
contribuir a estos debates, elucidando el rol de la experiencia estética en la comunicación sobre sostenibilidad. ${ }^{4}$

En este contexto, las artes se presentan como esfera clave para practicar y (re)pensar la comunicación sobre la (in)sostenibilidad. A pesar de la persistente discusión teórica sobre tal potencial (Kagan y Kirchberg, 2008; Thomsen 2015; Blanck y Benish, 2017), ése todavía no ha sido consecuentemente abordado por investigaciones científico-sociales de corte empírico -dejando en tela de juicio si, cuándo y cómo ese potencial se realiza. Es por ello que exploramos, en el presente artículo, la problemática de la sostenibilidad a partir de la experiencia estética desde la perspectiva del público receptor. Siguiendo al argumento de Clammer (2014) por una sociología y antropología desde el arte, nuestro análisis se basa en los resultados de una investigación-acción puesta en práctica a través del montaje de una exhibición de arte contemporáneo en Valparaíso, Chile, y el estudio empírico de la experiencia estética de su público. ${ }^{5}$ Visitada por más de nueve mil personas en 2017 en el Parque Cultural de Valparaíso (PCdV), la muestra ¡ejemplos a seguir! expediciones en estética y sostenibilidad reunió 62 trabajos de diferentes artistas, presentando un panorama internacional de posiciones sobre el DS.

El artículo comienza con una breve sinopsis de los debates locales e internacionales alrededor del concepto de DS (2). Enseguida, trazamos un cuadro de discusiones teóricas sobre el rol de la experiencia estética y artística en el contexto de la sostenibilidad, además de consecuencias para el abordaje empírico del tema (3). Luego, examinamos la recepción de la exposición jejemplos a seguir! en Valparaíso, enfocando las obras que tuvieron mayor repercusión en el público (4). Ello nos permite discutir los (des)entendimientos frente al concepto de sostenibilidad y los límites de las posibilidades de acción pro-sostenible articuladas por el público (5). En conclusión, hacemos un balance del potencial sociopolítico de la experiencia artística, así como de las dificultades que trae el concepto de sostenibilidad en el contexto local porteño y chileno (6). El pensar fuera de la burbuja, como lo sugiere en especial el arte contemporáneo, comprueba

\footnotetext{
${ }^{4}$ En Chile, usualmente se ha utilizado el concepto de sustentabilidad como sinónimo de sostenibilidad. Por ello, la gran mayoría de las iniciativas nacionales (institucionales o privadas) utilizan el primer término. Sin embargo, a nivel internacional el uso de sostenible goza de mayor legitimidad (Valcarcel, 2006: 18), incluso es usado en la Agenda 2030, por lo que optamos por hacer uso de éste.

${ }^{5}$ El montaje de jejemplos a seguir! en Chile se dio gracias a la colaboración de diferentes organizaciones, principalmente el IASS Potsdam, la Fundación Heinrich Böll, el PCdV y el equipo de la muestra.
} 
su relevancia; visualizaciones artísticas de cuestiones socioambientales internacionales pueden de hecho ser potentes vehículos de comunicación sobre sostenibilidad y agentes de cambio político-social. No obstante, su recepción e impacto se ven también condicionados (y limitados) por comprensiones y discursos preconcebidos localmente.

\section{Debates de sostenibilidad a nivel global, nacional y local}

El discurso internacional contemporáneo

La noción de DS en su sentido contemporáneo no se acuña antes de los años 70 del siglo XX, siguiendo dos olas importantes de, primero cientización, y luego, movilización pública que formaron el ambientalismo (Robin, 2018). El Club de Roma, en su célebre informe, emplea la palabra "sostenible" solo cuatro veces, pero con énfasis peculiar, equiparando la idea de sostenibilidad a la de estabilidad ecológica y ausencia de colapso (Meadows, Meadows, Randers y Behrens 1972:158). En un segundo plano, los autores también articulan la idea de que un "sistema mundial sostenible [deberá ser] capaz de satisfacer las necesidades básicas de toda la gente" (Meadows et al. 1972: 158, énfasis nuestro), pero es solo algunos meses después de la publicación de los Límites del crecimiento, luego que las tensiones entre ambientalismo y desarrollismo estallaran en la Conferencia de Estocolmo, que ese segundo aspecto empieza a avanzar en la formación de la idea moderna de DS. Cobra centralidad en las deliberaciones del Consejo Mundial de Iglesias, enriqueciendo la idea de sostenibilidad con acepciones de justicia e igualdad global de oportunidades (Grober, 2012: 176-178). Y es así como aparece en las formulaciones clásicas de la Comisión Brundtland, que después de consultas públicas en varios países del mundo llega a definir el DS como un "desarrollo que satisface las necesidades del presente sin perjudicar la habilidad de futuras generaciones de satisfacer las suyas" (Naciones Unidas, 1987: §1), implicando que el desarrollocrecimiento actual sea "menos intensivo en energía y materiales y más equitativo en su impacto" (Naciones Unidas, 1987: §35, énfasis nuestro).

Entonces sostenibilidad ya no equivale, simplemente, a estabilidad ecológica; la justicia, tanto intra como intergeneracional, avanza hacia un primer plano de la discusión. Incluso puede observarse que, a lo largo de 25 años del Proceso de Río, los temas ambientales retroceden en cuanto a su peso relativo en los documentos clave; en la Agenda 2030 y los Objetivos de Desarrollo Sostenible (ODS), la semántica ambiental ya se ve subordinada a temas de infraestructura, de acceso a servicios y distribuciones equitativas (Rivera, 2015: 12). La tendencia de negar o diluir los límites globales del crecimiento también 
deja su impronta en el discurso, empezando con la noción de los tres pilares inventados en los años noventa y reforzados en la Cumbre de Johannesburgo en 2002, que permiten que los más opuestos intereses puedan encontrar un escenario de convivencia contestada en torno al "significante vacío" que es la sostenibilidad (Kronfeld-Goharani, 2015: 317-319). Aquellos límites, mientras encuentran una expresión aparte en las llamadas fronteras planetarias, ya no forman el núcleo inequívoco de los discursos oficialistas. El Acuerdo sobre el Cambio Climático, que había nacido en Río, se desacopla de la Agenda 2030, y el crecimiento económico, aunque puesto en duda desde la ciencia y el ambientalismo, se consolida como parte del discurso.

La resultante hiperpluralidad de temas y enfoques se observa no solo en el oficialismo de Naciones Unidas y en las docenas de estrategias nacionales de DS; las voces críticas desde las sociedades civiles también apuntan a cuestiones ya no confinadas al medio ambiente en el sentido de participación ciudadana, desigualdades entre esferas urbanas y rurales, de género, de educación, de patrimonio cultural, etc. Con respecto a ese discurso vigorosamente globalizado y politizado - en el sentido de que acoge una multitud de desigualdades sociales y ambientales ${ }^{6}$ - una exposición como jejemplos a seguir! adquiere casi algo como representatividad por su carácter internacional y multifacético, y por el contenido social y la forma discursiva de muchas de sus obras. ${ }^{7}$

Antecedentes de la discusión pública en Chile

La sostenibilidad como término y, con ella, los nexos entre el medioambiente y las cuestiones sociales, aparecen en Chile a fines de los noventa (Observatorio de Sostenibilidad, 2016: 22), en reacción al Proceso de Río y a presiones de organismos internacionales. En este contexto podemos distinguir tres grupos de actores centrales: institucional, privado y social. El avance en materia institucional ha sido bastante lento. Un ejemplo es que recién en el año 2010, y gracias a las presiones de la OCDE por los resultados de la

\footnotetext{
${ }^{6}$ Dado que esa acogida es hiperincluyente y tiende a tapar contradicciones importantes entre diferentes reclamos y metas, los debates, sin embargo, pierden cognoscibilidad - un efecto que podríamos denominar despolitizador (Rivera, 2015).

${ }^{7}$ Ya la obra titular de la exposición - Under discussion - señala ese espíritu. Comentándola, los artistas latino-estadounidenses Jennifer Allora y Guillermo Calzadilla preguntan: “Cuando se marca un territorio, ¿el interés de quién y qué objetivo sirve?” Veremos más adelante cómo esa dimensión territorial-conflictiva, tan importante para América Latina y Chile, se pierde en la recepción local de la muestra.
} 
Evaluación de Desempeño Medioambiental a la que sometió a Chile en el año $2005^{8}$ (Biblioteca del Congreso Nacional, 2010), se promulga la Ley 20.417, que crea el Ministerio del Medio Ambiente, además del Servicio de Evaluación Ambiental y la Superintendencia del Medio Ambiente, hecho importante no sólo porque salda una deuda pendiente, sino porque el Ministerio se convierte en la primera institución que tiene como principio de base la promoción del DS (Biblioteca del Congreso Nacional, 2010).

En cuanto a política exterior, Chile ha participado en convenciones internacionales y ha firmado acuerdos multilaterales siguiendo la agenda medio ambiental global (Chile Desarrollo Sustentable, 2017). La gran mayoría de los firmados antes de la Cumbre de Río en 1992 se centran en la preservación de la biodiversidad y protección de flora y fauna nativa y no hacen referencia a problemas de desarrollo. Posterior a dicha cumbre, los acuerdos se enfocan en la mitigación de impactos medioambientales de la actividad productiva y la búsqueda de estrategias para evitarlos, en sintonía con el reconocimiento de la sobreexplotación de los recursos como un problema global.

No obstante, los avances en materia legislativa han sido pocos e incluso se han experimentado retrocesos. En el año 2012 se firmó la Nueva Ley de Pesca, que originalmente, pretendía incorporar el concepto de pesca sustentable. Sin embargo, se aprobó una ley - con el disgusto de los pescadores artesanales - que en materia de recuperación de recursos sobreexplotados establece licitaciones de cuotas de pesca y beneficia principalmente a las grandes pesqueras. Esto demuestra que el sector privado en Chile tiene un peso sustantivo en la discusión política, a pesar de su muy tardío involucramiento en las discusiones sobre sostenibilidad (Arriagada, 1992: 54). La discusión poco profunda, centrada en quién puede usufructuar del recurso más que en el cómo hacerlo (Molina, 2012), muestra un sector privado que abusa de la laxitud del concepto de sostenibilidad, ciñéndolo exclusivamente a su dimensión económica y a sus respectivos indicadores. Aunque esa tendencia también se nota a nivel internacional, es mucho más marcada en Chile, en el sentido de que lo macroeconómico oculta los reclamos sociales.

\footnotetext{
${ }^{8}$ La evaluación (realizada en conjunto con la CEPAL) resultó en 52 recomendaciones para Chile que condicionaban su ingreso a la OCDE. Éstas tenían por objeto mitigar los problemas ambientales producidos por el crecimiento económico experimentado desde 1990 y giraban en torno a la gestión ambiental, el DS y el fortalecimiento de acuerdos internacionales.
} 
El abrumador peso de las empresas se refuerza en la debilidad de otros sectores y deja de manifiesto la tensión existente entre el estado conservacionista en el discurso, pero permisivo en sus acciones (Observatorio de Sostenibilidad, 2016), poniendo en duda la posibilidad de existencia de un capitalismo transformador. No fue hasta comienzos de este siglo cuando el concepto de Responsabilidad Social Empresarial (RSE) aparece en el quehacer del empresariado, y recién en el año 2013 se creó el Consejo de Responsabilidad Social para el Desarrollo Sustentable organismo de carácter público-privado y participativo, encargado de promover y coordinar acciones en materia de RSE (Observatorio de Sostenibilidad, 2016). Otras iniciativas se pueden rastrear hasta el 2005 con los Reportes de Sustentabilidad, entre otras más recientes. A pesar de ello, el empresariado se ha mostrado abiertamente preocupado sobre los impactos financieros negativos que dichas medidas podrían traerles (Corvalán, Pérez-Cueto, y Fierro, 2015). Finalmente, fuera de las medidas de gestión de residuos y contaminación y algunas relacionadas con la RSE, aún depende de las empresas si adoptan una ética responsable frente a la sociedad y el medio ambiente y si contribuyen con medidas paliativas para los impactos de su producción. Incluso, muchas empresas utilizan estas medidas como un proceso de limpieza verde: aparecen públicamente preocupadas con el DS, cuando en lo práctico sus acciones se limitan a la autopromoción.

Por otro lado, varios actores de la sociedad civil han intentado visibilizar la necesidad de asumir el desafío del DS, teniendo con frecuencia la idea de justicia socioambiental como rector. Luego de Río 1992 comienzan a crearse organizaciones ambientalistas que se oponen al modelo económico extractivista implantado durante la dictadura militar y exigen avances en temas de control de emisiones, gestión de recursos y justicia social (Cuenca, 2011). En 1997 se fundó el Programa Chile Sustentable, una plataforma amplia de diferentes organizaciones que pretende aportar en el cambio del modelo de desarrollo chileno a uno basado en la sostenibilidad. Un gran número de organizaciones sociales se establecen como tales luego de ver afectados sus propios territorios por las consecuencias del extractivismo (contaminación, sequía, aridez de los suelos, etcétera) o para frenar el avance de las industrias en general. Cualquiera sea el caso, estas organizaciones se centran en la idea de la justicia social y también regional-anticentralista, desafiando el papel del estado. En otras palabras, entrar al debate sobre la sostenibilidad se realiza sobre una base ética que ve al medio ambiente como un "espacio de vida" (Sabatini, 1997), lo que se opone a la visión del empresariado que lo trata como un recurso del que hay que disponer. En la actualidad, el 
Instituto Nacional de Derechos Humanos (INDH) publicó en el año 2012 el Mapa de Conflictos Socioambientales en Chile, que pone a disposición de la ciudadanía y va actualizando la información acerca de los conflictos socioambientales abiertos o latentes (Instituto Nacional de Derechos Humanos, 2016). ${ }^{9}$ A pesar de que el seguimiento de estos conflictos nos muestra que se han reducido considerablemente en sus cifras (actualmente existen 102), no se tiene información oficial acerca de la manera en que se cierran los conflictos y si ésta responde o no a parámetros de justicia social.

Finalmente, cabe señalar que la opinión pública en cuanto es medida a través de encuestas, no se ve muy sintonizada con los conflictos y las iniciativas articuladas desde la sociedad civil. Pero las chilenas y los chilenos tampoco recuerdan avances en las políticas públicas. ${ }^{10}$ Una porción importante, casi mayoritaria declaran estar satisfechos con la situación del medio ambiente, porcentaje que, curiosamente, incluso va en aumento (DESUC: 40). Ello va de la mano de un optimismo marcado respecto del futuro ambiental (en comparación internacional) y con una percepción muy localista del tema, enfatizando la contaminación del aire y el problema de basuras (DESUC: 43, 28). Sin que podamos discutir sus orígenes políticos y mediáticos en este artículo, es notable que esa percepción es reproducida a través de los estudios mismos, que por completo omiten palabras como "justicia", "conflictos", o "sostenibilidad".

\section{Antecedentes en Valparaíso}

La problemática socioambiental en Valparaíso, históricamente, se ha ido articulando en torno a temas diversos, como las ineficaces estrategias para la limpieza de la ciudad y el tratamiento de residuos; la falla constante en la elaboración y aplicación de herramientas para la planificación urbana y, en consecuencia, la intensa segregación y el importante número de incendios que registra la ciudad; la desregulación inmobiliaria y de la agroindustria, ajenas cada vez más al territorio local, cuyas consecuencias aparejadas son la edificación en altura que arrasa con el patrimonio arquitectónico en el primer caso y la escasez del recurso hídrico, en el segundo. Todo esto ha dado lugar a la actuación de organizaciones con pertenencia

\footnotetext{
${ }^{9}$ Esfuerzos similares datan de 1988, con la creación del Observatorio de Conflictos Socioambientales, encargado de prestar asesoría a comunidades en conflicto para asegurar sus derechos ambientales. Durante este período la academia centraría sus atención en el diagnóstico de territorios afectados: en 1990 se finalizó el primero del país, que arrojó un total de 856 conflictos a lo largo de Chile (Camus \& Hajek, 1998). Son típicos para América Latina en general, tal como lo es el desafío ideológico que esbozamos (ver también Barloewen y Rivera 2014: 30-33). Junto con los incentivos relacionados que la exposición misma ofrece (ver nota 6), ese hecho intensifica la necesidad de explicar, más en adelante, por qué esa dimensión no se refleja en nuestro estudio.

${ }^{10}$ Eso quiere decir que literalmente no los recuerdan/no saben ( $42 \%$ de los encuestados). Solo un $12 \%$, con tono crítico, constatan que "no han visto ningún avance" (DESUC: 114).
} 
local. Sin embargo, la emergencia de cada una de estas ocurre a propósito de conflictos específicos, hecho que nos lleva a plantear la siguiente pregunta: ¿Cuál ha sido la discusión pública sobre sostenibilidad en Valparaíso?

Aunque la problemática socioambiental de la ciudad posee larga data y se sitúa en el nivel estructural de la misma, el diálogo respecto al concepto "sostenibilidad" es reciente y ha estado marcado por el cumplimiento de los ODS. Así, el parámetro de lo sostenible en Valparaíso sigue el esquema de ajuste al mandato internacional emanado desde el gobierno central y, quienes disputan su significado, son quienes se encuentran organizados en las esferas civil, política y económica. En este marco, vemos al empresariado hablar de Valparaíso como un foco del Turismo de Intereses Especiales, el cual implica una sofisticación de la oferta "pero sin implicar riesgos para la sostenibilidad del territorio" (Gonzalez, Castro Romero, y Marín Toro, 2013). Esto estaría interpelando a las y los empresarios tour operadores y a las autoridades comunales que, en plena elaboración del Plan de Desarrollo Comunal, han fijado los ODS como lineamiento a seguir. De manera análoga, la Empresa Portuaria de Valparaíso elaboró el Plan Estratégico de Sostenibilidad, cuyo objetivo "es asegurar en el largo plazo la viabilidad del negocio de Puerto Valparaíso y contribuir al desarrollo sostenible” (Empresa Portuaria de Valparaíso, 2016, p. 1).

En cuanto al patrimonio, la Agrupación de Arquitectos y Profesionales por Valparaíso señaló que en coherencia con los resultados de la Conferencia de Naciones Unidas Hábitat III, el desarrollo urbano constituye un paso decisivo para alcanzar un DS integral (Plan Cerro, 2017). La Agrupación también ha sido activa en la discusión del ODS "Ciudades y comunidades sostenibles", por ejemplo en un seminario nacional sobre el tema, que discutió principalmente la preparación de las ciudades chilenas ante el cambio climático (BCN, 2017).

Además, desde las organizaciones de la sociedad civil de la V Región se ha instalado con más fuerza en los últimos cinco años el relato en torno a la problemática del agua, cuestión que podemos ver a través de campañas como "SECOS", realizada por la agrupación MODATIMA con apoyo de figuras del ámbito artístico nacional y que ha visibilizado la sequía en el Valle del Aconcagua. Por su parte, podemos ver también las protestas organizadas en contra del proyecto energético de la termoeléctrica Los Rulos, lo cual ha tenido como protagonistas a las comunas de Limache, Villa Alemana y Quilpué. 
Finalmente, es interesante notar los resultados en Valparaíso del programa "Yo opino, es mi Derecho", dirigido a niños, niñas y adolescentes ${ }^{11}$ con el fin de involucrarlos en la Agenda 2030 y los ODS (Consejo Nacional de la Infancia, 2017). En dicho espacio, y entre un grupo de problemáticas ambientales predefinidas, las y los estudiantes porteños más pequeños destacan como prioritarios los asuntos relacionados con el fin de la pobreza, la preocupación por los ecosistemas terrestres, el agua limpia y la acción por el clima. Por su parte, para las y los más grandes, destaca la reducción de las desigualdades, la creación de ciudades sostenibles así como el trabajo decente (Consejo Nacional de la Infancia, 2017).

De esta forma y a través de estos temas es que comienza a darse la discusión sobre sostenibilidad en la comuna de Valparaíso. Su carácter incipiente y el despliegue que ha tenido la institucionalidad en ella contrasta con el tratamiento histórico de específicas problemáticas ambientales y urbanas que la ciudad ha experimentado a lo largo del tiempo, y que ha mantenido y mantiene hasta hoy, movilizada a la sociedad civil. Ese contraste implica que no todas las problemáticas y conflictos presentes repercutiesen en la opinión pública cuando se habla de sostenibilidad o de medio ambiente, hecho que ya observamos con vistas a las encuestas nacionales. En estas, la V Región ocupa un lugar promedio en casi todas las respuestas (es decir, es típica del país entero).

\section{Arte y sostenibilidad}

A continuación, intentamos echar luz sobre las posibles sinergias entre la comunicación sobre problemas globales de insostenibilidad y la experiencia estética. Como explica Rebentisch (2013), el concepto de la experiencia ha ganado mucha importancia en los estudios de estética de recepción, especialmente a partir los años 1970. Desde el surgimiento del arte moderno y contemporáneo, que a menudo juega con cuestiones de percepción, validez, expectativas, prejuicios etc., los estudios de la forma de los objetos artísticos han sido crecientemente complementados por miradas centradas en la interpretación del público. Ello se corresponde con la creciente tendencia de producir "obras de arte abiertas", que, como define Umberto Eco, son obras de arte que se proponen solamente realizarse concretamente a través de la intervención del receptor-intérprete (Eco 1973: 27-58). Esa apertura de significación en objetos artísticos nos remite a repensar "la potencialidad semántica” en la experiencia estética, que nunca ha sido más

\footnotetext{
${ }^{11}$ La convocatoria fue realizada por el Consejo Nacional de la Infancia y el Programa de Naciones Unidas para el Desarrollo (PNUD), en colaboración con el Ministerio de Educación, el Ministerio de Desarrollo Social, la UNICEF y la OEI.
} 
significativa que en el arte contemporáneo (Rebentisch 2013:34: 167). Así, para discutir los potenciales de este arte en el contexto de la comunicación sobre sostenibilidad, trataremos en seguida de dos aspectos principales (e intrínsecamente interconectados) de la experiencia estética: el potencial de evocar sensaciones y el potencial de hacer reflexionar.

La sensibilidad en la experiencia estética: Potencial expansivo

Valorar la dimensión de la experiencia en el arte contemporáneo implica apreciar su capacidad de activar, intensificar y definir sensaciones y emociones (Blanck y Benish 2007: 5). Respecto del abordaje de la (in)sostenibilidad por intervenciones artísticas, el ámbito de los sentidos ha sido considerado clave por diferentes autores (Leyda, Loock, Starre, Barbosa, y Rivera 2016; Thomsen, 2015; Kagan, 2013; Kenbusch, 2008). Mientras que la sensibilidad en sentido estricto ha sido enfocada por las y los autores que escriben en diálogo con una tradición filosófica y de estudios culturales sobre el estético, otros estudios sobre comunicación ambiental han enfatizado más el rol del afecto y las emociones (Hansen y Cox, 2015; Salama y Aboukoura; 2018). En el presente artículo, partimos de discusiones sobre lo sensorial-perceptual, pero también consideramos las emociones como un concepto íntimamente relacionado a la sensación.

Por su difícil percepción en la experiencia diaria de gran parte de la población mundial, el cambio climático ha ganado especial atención en estudios sobre abordajes artísticos y comunicativos. Kagan (2013: 30) resalta el trabajo de la artista Andrea Polli, autora de una instalación que traducía datos sobre variaciones climáticas a diferentes tipos y niveles de sonido, que podrían ser sentidos por el público. Y Kenbusch, por ejemplo, destaca el crecimiento del rol de las emociones en producciones artísticocientíficas dedicadas al tema clima, estrategia que el autor ha observado recientemente en diferentes museos de ciencia, como en la exhibición Climax (2013) en la Cité des Sciences et de l'Industrie, que pretendía provocar que sus visitantes sufrieran un "choque climático" (Kenbusch 2008: 243). Por otra parte, si miramos producciones culturales populares, más allá del arte visual, el emergente género de literatura y cine $c l i-f i$, o clima ficción, también fuertemente recorre a un llamado emotivo para abordar escenarios -generalmente distópicos- de insostenibilidad planetaria (Leyda et al. 2016). En general, las "[e]mociones son modeladas, expresadas, canalizadas, hasta identificadas, por sus manifestaciones artísticas" (Clammer 2014: 14). Además, las emociones contribuyen al ordenamiento y la estructuración 
de la esfera de la experiencia, evaluando y conduciendo las percepciones, y así complementando la cognición intelectual (Hamker 2003: 37); he aquí su nexo con las sensaciones en sentido estricto.

La emoción de empatía, en especial, ha sido muy explorada en la teorización sobre -y la práctica delarte en la temática de (in)sostenibilidad (por ejemplo, Thomsen 2015). Explorando la empatía como forma de percibir conexiones, Kagan (2013: 27) propone pensar la estética como "sensibilidad para el padrón que conecta"; tal sensibilidad en el contexto del arte sobre sostenibilidad implicaría, pues, no sólo percibir padrones que conectan el observador con otros seres y ambientes, sino también visibilizar las conexiones entre distintos seres y procesos alrededor del planeta. De ese modo, la experiencia estética propulsada por obras de arte que abordan la ecología se constituye en "una experiencia expandida de la realidad", lo que resulta en un "modo expandido de conocimiento" que es imprescindible en el entendimiento de los complejos problemas de la insostenibilidad. Para Kagan (2013: 218), "la contribución del arte a una cultura de la sostenibilidad se puede encontrar especialmente en su potencial para crear experiencia, establecer relaciones, expandir la actividad mental más allá de los límites lineales de la conciencia intencional." Así, el carácter sensible -e indirectamente reflexivo- de la experiencia estética es imprescindible para marcar de manera transformadora a la persona que experimenta. Con respecto al concepto de DS, vemos que esa expansión de la inmediatez se extiende, potencialmente, no solamente a la naturaleza o al espacio físico, sino también a otros seres humanos y espacios sociales; el concepto de empatía no solo reclama vigencia para el ambientalismo de corte clásico, sino también aplica a lo socioambiental.

Más allá, la dimensión sensitiva e intuitiva de la experiencia estética ha sido considerada crucial para la imaginación y transformación sociopolíticas. Para Clammer (2014: 13), aunque buena parte de lo que él llama “imaginación social” en práctica se limita a utopías y ciencia-ficción etc., enteras realidades sociales -entre ellas prácticas socioeconómicas como el capitalismo o socialismo- - se formaron también a partir de articulaciones imaginativas. En la misma dirección, Marcuse (1969: 29) considera que cualquiera sea la forma de realidad proyectada por la imaginación, ella será siempre derivada de una experiencia sensitiva. Aludiendo a las movilizaciones políticas de los años 60, Marcuse vislumbra en lo estético "la posible forma de una sociedad libre"; la sensualidad de lo estético sería crucial para superar la actual represión del sistema social y así imaginar otras formas de vivir en sociedad (Marcuse 1969: 23-25). Asimismo, Pérez Carreño pondera que "lo valioso de la actividad artística [...] es su capacidad para crear 
nuevas formas de comprensión del mundo [y de modificar] la visión de la realidad, hasta [...] recrearla" (1999: 106).

De ahí que la imaginación activada por la sensibilidad artística pueda cumplir un rol importante si nos proponemos imaginar otro futuro diferente de los escenarios de insostenibilidad global. Ambas dimensiones centrales para el discurso DS contemporáneo, la diversidad (y desigualdad) global y las representaciones (y los desfases) del futuro, son fundamentales. Lo espacial y lo temporal, limitados en la experiencia cotidiana, se expanden a través del arte.

\section{Experiencia estética y reflexión: Potencial crítico}

En su libro El arte del ambiente, Kepes (1972: 6) nota que las artes "pueden ser vistas como uno de los recursos colectivos auto-reguladores básicos que nos ayudan a registrar y rechazar lo que es tóxico y encontrar lo que es útil y significativo en nuestras vidas". En ese mismo sentido, diversos autores destacan las artes como una herramienta primordial para generar reflexión frente a problemas socio-ecológicos. Por ejemplo, Kenbusch (2008: 243), considerando distintos ejemplos de exposiciones de arte sobre cambio climático, resalta que "el arte puede nos ayudar a cuestionar nuestras [...] relaciones con el clima y sus modificaciones [...], deconstruyendo nuestra percepción común y revelando otras percepciones posibles sobre ello".

Mezclando lecturas sobre percepción, cognición y arte, Zschocke llega a similares conclusiones en su estudio sobre la confusión visual como estrategia en el arte contemporáneo. La autora argumenta que el tomar consciencia sobre incertidumbres o trastornos en la percepción causa procesos de pensamiento reflexivo: nuevas cuestiones son levantadas y antiguas suposiciones dejan de ser obvias. Zschocke resalta que objetos inusitados que contradicen la idea de un mundo estable y obvio son vivenciados y descritos como "incómodos", y pueden catalizar sensaciones de duda, fascinación o mismo asombro. Pero es exactamente mediante incertidumbre y desorientación que se da un potencial transformador en la recepción de un objeto artístico: el observador se aventura a nuevas reflexiones para encontrar soluciones al problema cognitivo establecido, lo que inicia un proceso de cambio en la experiencia cotidiana En especial la situación de ambigüedad o de contradicción indisoluble puede desestabilizar un sistema de ordenamiento o significación, y poner el observador en la situación de desarrollar nuevas concepciones, 
concluye Zschocke (2016: 89-91). En la misma dirección, Eco (1973: 40-41) argumenta que ambigüedad es característica componente de muchas “obras abiertas", y cita como ejemplo la situación final de diversos dramas de Brecht: terminan en un problema de existencia social que carece de una solución, y cabe a los espectadores sacar sus conclusiones. Así, Eco (1973: 50) recorre a estudios en la psicología cuando argumenta que la "ambigüedad perceptible" presenta "la capacidad de emerger de la convencionalidad de la cognición habitual, para comprender el mundo con un frescor de posibilidad que precede a cualquier concepción determinada por el hábito".

Ya en las teorías estéticas de Kant y de Adorno (1970), la reflexión ha sido conceptualizada como parte integral de la experiencia estética. Mientras Kant habla del "juicio reflexionante" como elemento constituyente de la experiencia estética (citado en Bubner 1989: 36), Adorno resalta que el objeto de arte se define por su "carácter de enigma” (Adorno 1970: 182). Según Rebentisch (2013), dicho carácter puede también ser consumado por medio de un abordaje lúdico: la autora narra el ejemplo del grupo Critical Art Ensemble, que en una performance simuló un laboratorio de transgénesis. Como en un juego, la performance llevó el público a preguntarse: ¿sería eso una escena artística o un establecimiento científico? Así, la obra estableció una ambigüedad que sólo podía solucionarse a través de la reflexión del público. Para Rebentisch, esta y varias otras obras de arte contemporánea en los últimos tiempos, que fluctuando sobre las fronteras entre la ciencia y las artes, logran "su potencial político a partir de la distancia reflexiva" (Rebentisch, 2013: 217).

En suma, tanto la sensibilidad como la reflexión son elementos constitutivos de la experiencia estética, sirviéndose de mecanismos específicos como la inmediatez, la empatía, la contradicción o la ambigüedad, y coproduciendo resultados clave como la imaginación de otro(s) mundo(s), la expansión de la representación, y el aumento de la capacidad crítica. En las obras de arte que dialogan con la sostenibilidad, en particular, esos resultados (posibles) se corresponden de manera promisoria con los retos de la transformación radical, de la perspectiva global, y la necesidad de tratar con múltiples niveles la desigualdad y reclamos de justicia.

Implicaciones metodológicas

A partir de las consideraciones sobre sostenibilidad y estética desarrollados más arriba, trazamos una metodología para el análisis de la recepción de una exposición artística internacional sobre sostenibilidad 
en Valparaíso, a saber jejemplos a seguir! - expediciones en estética y sostenibilidad. En primer lugar, la decisión de instalar una exposición internacional en el contexto porteño tenía el objetivo de hacer posible la investigación de la recepción local de un discurso internacional sobre sostenibilidad, materializado y visibilizado aquí en las 62 obras de la exposición. Concebida en un proyecto de investigación-acción, la estación chilena de la muestra fue acompañada por una serie de conversatorios y otras actividades de diálogo abiertas al público, la que reunió a invitadas e invitados desde Chile y del exterior, de las artes, ciencias, política y movimientos sociales a discutir algunas cuestiones sobre sostenibilidad abordadas por parte de la sociedad chilena (p. ej. conflictos territoriales o gobernanza del agua) y en algunos casos también por artistas de la muestra (p. ej. basuras o cultivos agrícolas).

¡Ejemplos a seguir! fue concebida por la curadora alemana Adrienne Goehler como una exposición itinerante, desde 2010. Aparte de varias estaciones en Alemania, ha sido montada en Brasil, México, Perú, India, Etiopia y China, y cada estación incluyó nuevas obras de artistas del respectivo país. La muestra contiene obras con diversos medios, abordajes y temas de sostenibilidad, y reúne a más de 60 artistas, artistas-científicos y artistas-activistas, entre ellos nombres ya consagrados internacionalmente como Joseph Beuys, Robert Smithson, Ólafur Ellíason, Francis Alÿs, Superflex, Ravi Agarwal y Pedro Reyes. ${ }^{12}$

Ese marco nos permite entender los matices de la recepción del público en Valparaíso como una respuesta local a un impulso artístico internacional. Inspirados por la literatura discutida arriba, hemos escogido un enfoque metodológico que proporcionara espacio para el registro de las más diversas manifestaciones del público-receptor. El análisis se basa en la triangulación de los siguientes métodos:

1) cuestionarios estandarizados, ubicados para auto-aplicación en la salida de la sala de la exposición y cumplimentados por 260 visitantes. Comprendiendo seis grupos de preguntas que generaron datos generales cualitativos y cuantitativos sobre la experiencia (emotiva e intelectual) de la exposición en general, y también de las obras que más despertaron interés. Este método tenía la función de generar una visión conjunta del público y así orientar el análisis de los otros métodos;

2) entrevistas semiestructuradas, realizadas con al menos 36 visitantes en el espacio de la exposición. Las entrevistas contenían preguntas sobre la motivación de la visita, la recepción de las obras que más llamaron

\footnotetext{
${ }^{12}$ Ver Demos (2017) para un análisis de obras de eses artistas y de exposiciones dónde fueran presentadas.
} 
la atención (en preguntas hechas frente a las obras nombradas por el entrevistado), y aprendizaje en general sobre sostenibilidad a través de la exposición;

3) grupos focales, realizados en tres sesiones cada una, con tres a cinco visitantes de la exposición, donde las preguntas de las entrevistas se discutieron libremente, además del concepto de sostenibilidad. Ambos métodos 2 y 3 comparten la función de explorar la experiencia estética del público y su conexión con el tema sostenibilidad; ${ }^{13}$

4) observaciones en el programa de actividades que acompañó la exposición jejemplos a seguir!, en especial de cinco conversatorios, así como de una visita guiada y taller realizados para un grupo de estudiantes. Ese método funciona aquí como una variable de la resonancia y repercusión discursiva locales del proyecto de la exposición.

\section{La recepción de ¡ejemplos a seguir!}

La exposición fue visitada por más de nueve mil personas, siendo la muestra con mayor público registrado en el PCdV. ${ }^{14}$ En relación con el perfil del público, $42 \%$ de las y los encuestados tiene entre 21 y 30 años, siendo la media de edad 32. El 41\% vive en Valparaíso, seguido por Viña del Mar (16\%) y otras comunas de la V Región (18\%), y Santiago (16\%). En cuanto a la ocupación, 44\% son estudiantes; los profesionales de cultura y artes representan $18 \%$ y los educadores $10 \% .{ }^{15}$ En cuanto a la percepción de obras, las más mencionadas positivamente en los cuestionarios fueron: The Guide del artista Clement Price-Thomas (presente en $17 \%$ de todas las menciones), Greenbag Movement de Dodi Reifenberg (9\%), The Infinity Burial Project de Jae Rhim Lee (7\%), Solar-Powered Electric Chair de Christian Lahr (5\%), y Where traditional species die out, mankind looses something of its history and culture de Ursula Schulz-Dornburg (6\%). Juntas, suman casi la mitad del total de 282 menciones a casi 60 obras distintas. A continuación, analizamos la experiencia estética del público mediante las cuatro primeras obras, que también fueron discutidas en mayor extensión y profundidad por las y los entrevistados y participantes de grupos focales. ${ }^{16}$

\footnotetext{
${ }^{13}$ Los audios de entrevistas y grupos focales fueron transcritos, y analizados inductivamente vía el software MAXQDA.

${ }^{14}$ En la relación al impacto en la prensa, la muestra obtuvo una buena crítica nacional e internacional, en las cuales se alude a la larga trayectoria de la exposición presentada en distintos países, así como la incorporación de artistas chilenas y paneles de diálogos. La muestra también recibió el premio de mejor exposición internacional del año por el Círculo de Críticos de Arte de Chile.

15 La encuesta no es representativa y sirve solo para caracterizar nuestra base cualitativa de datos. Conforme a nuestras observaciones a lo largo del programa de diálogo y de las entrevistas, sí hubo una asistencia superior de jóvenes, pero no tan marcada como en estos datos.

${ }^{16}$ No abordamos en profundidad la obra de Ursula Schulz-Dornburg no solamente debido a la falta de espacio, sino también porque el material colectado no nos dio tanta visión sobre la experiencia del público como las otras cuatro obras. En general,
} 


\section{The Infinity Burial Project}

Entre las obras de jejemplos a seguir! aquí analizadas, The Infinity Burial Project [El Proyecto Entierro Infinito] fue la tercera más mencionada en los cuestionarios y la segunda más extensamente discutida con el público en la recopilación cualitativa (en promedio por entrevista o grupo focal). Los y las entrevistados se refieren a ella como: "la obra del cuerpo ese en descomposición”, "la del cadáver y los hongos", "el traje de sepultura de hongos", o también como "el entierro biodegradable". En las palabras de su autora Jae Rhim Lee, la obra es "una propuesta modesta en la intersección del arte, la ciencia y la cultura” que básicamente propone un sistema de entierro alternativo que usa hongos para descomponer y limpiar toxinas en cadáveres. Lee recuenta que la idea del proyecto nació después de que se enteró que un ciudadano norteamericano tiene a lo largo de su vida en promedio "219 contaminantes tóxicos en el cuerpo, y esto incluye conservantes, pesticidas y metales pesados como plomo y mercurio." Según la artista, eso implica que "somos responsables y víctimas de nuestra propia contaminación” y que, después de nuestra muerte, "las toxinas vuelven al medio ambiente para continuar el ciclo de toxicidad."17

La instalación de Inifinity Burial presentada en Valparaíso contiene una caja transparente rectangular, dentro de la cual se ve un ejemplar de un traje negro con un alambrado de crochet blanco incrustado con esporas de hongos, cuyo diseño imita el crecimiento del micelio de hongos, que se asemeja a las raíces de las plantas. El traje reviste a un muñeco yacente, del cual sólo se ven las manos, de apariencia humana. Dentro de la caja se ven además pequeños potes de vidrio con restos de piel humana y cultivos de hongos. Afiches en la pared explican el procedimiento: antes de su muerte, la persona que va a vestir el traje debe cultivar hongos a partir de su piel, pelo y uñas, adaptándolos para consumir sus restos mortales. Los hongos son aplicados en el traje mortuorio y con el tiempo devoran el cadáver, transformándolo en suelo libre de toxinas.

\footnotetext{
los comentarios se limitan a su estética de ordenamiento taxonómico-museológico, a su técnica de fotografía y a su impresionante esfuerzo de ejecución. Aun así, un pequeño número de entrevistadas, a propósito de la obra, reflexionaron sobre la producción industrial de alimentos y biodiversidad, haciendo también un puente con la problemática en Chile.

17 Presentación de Jae Rhim Lee "My mushroom burial suit", TEDGLOBAL 2011. Recuperado de: https://www.ted.com/talks/jae_rhim_lee/up-next. Acceso: 03 Ago 2018.
} 


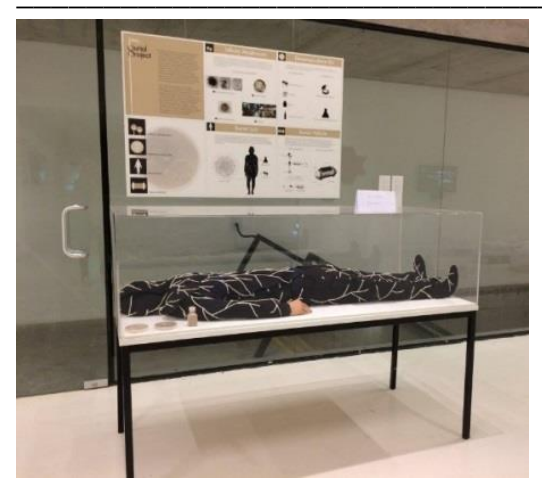

Figura 1: The Infinity Burial Project. Fuente: jejemplos a seguir! [zne!]

Para varios visitantes, la primera reacción fue de intriga y misterio. Para otros, la impresión fue de impacto: consideraron la obra "heavy" o "muy fuerte". Algunos describieron la sensación de ver esta obra con el adjetivo "raro", es decir, como extrañeza. Una entrevistada resaltó que observar la caja le dio una sensación de desconcierto e incomodidad. En una visita guiada con un grupo de estudiantes del $5^{\circ}$ y $6^{\circ}$ básico, niños y niñas se aglomeraron alrededor de la instalación, y, con las manos sobre la caja, observaron boquiabiertos "el cadáver".

En uno de los grupos focales, el relato de una visitante señala el potencial de la obra para generar reflexión: "El asunto de la muerte, que fue lo que más me impresionaba a mí, de ver los cuerpos - porque no sé si ustedes piensan en qué es lo que va a pasar con su cuerpo cuando mueran, pero a mí me da miedo que me saquen los dientes [...] [risas] Entonces la obra era como mucho más, no sé, perturbadora. [...] Te daba para pensar y soñar”. [Énfasis nuestro.]

Otras reacciones del público demostraron el proceso de repensar las prácticas funerarias corrientes. A la pregunta si tuvieron algún aprendizaje sobre la idea de sostenibilidad a partir de la visita a la muestra, cuatro entrevistados mencionaron la obra de Lee. Una visitante, por ejemplo, reflexionó sobre cómo los “entierros con ataúdes [...] no están tan bien” y sobre cómo la técnica del Infinity Burial podría "crear otro tipo de sustentabilidad". Esta y otras observaciones similares se corresponden con reflexiones sobre la insostenibilidad de los rituales de muerte propuestas por Lee, que resalta: "en un funeral estadounidense tradicional, un cuerpo sin vida se cubre con rellenos y cosméticos para que parezca que está vivo. Luego se lo bombea con formaldehído tóxico para retrasar la descomposición [...]. Por tratar de conservar nuestros cuerpos sin vida, negamos la muerte, envenenamos a los vivos, y dañamos al medio ambiente" 
Como pone de manifiesto Barnett (2018) en una lectura de The Inifinity Burial Project, las prácticas convencionales de entierro ofuscan la íntima relación entre cuerpos humanos y medio ambiente. La obra deconstruye la separación binaria entre humanos y naturaleza, tanto en la presentación del problema como en la propuesta de solución. Por un lado, Lee deja claro que la acción de las toxinas que ingerimos transgrede no solo las fronteras de nuestro cuerpo sino también del tiempo de la vida humana, continuando en el ambiente en el post-mortem. Por otro lado, la obra consiste en el proceso de transformación de los cuerpos humanos, mediado por la descomposición hecha por otros seres aún vivos, los hongos. Así, el enfoque de la obra de Lee está en la transición de la materia. En vez de incomodarse con el tabú de la indefinición del estado transicional -asociado a impureza-, Lee lo abraza y lo resignifica de manera positiva: un cuerpo puede ser alimento para otros seres, puede transformarse en tierra fértil (Barnett 2018). El siguiente extracto de la conversación con una de las entrevistadas más impresionadas con la obra ejemplifica la reflexión sobre estos puntos desde la experiencia estética:

"Es que como las líneas blancas ... [pausa] es como que siento que las raíces se están como apoderando del cuerpo. [...] De todo lo que veo, es como lo que más se puede poner como en práctica, lo que uno más puede decir, así como "ah, veo esto y en verdad se puede lograr", es algo concreto. [...] Siento que cuando uno muere [...y] no hay alma, no hay nada más que cuerpo, más que carne y eso, entonces, en vez de darle un mal uso o no darle uso dentro de una caja, se podría dar uso mejor a la tierra para aprovecharse como nutriente para poder que se creen nuevas materias orgánicas."

Así, la obra fue recibida por el público también a partir de una reflexión sobre su posibilidad de aplicación práctica. Visitantes resaltaron su carácter innovador como "reciclaje del cuerpo humano", y discutieron, en un grupo focal, quién se pondría el traje de hongo.

Entretanto, esa aplicabilidad no fue del todo clara para todo el público. De hecho, la atención de muchos tuvo que ver con dudas. En la sala de exposición, la obra se ubicaba cerca de otras obras más o menos aplicables en un futuro próximo o distante - entre ellas una lavadora acoplada a una bicicleta, y "Dermoherba", una propuesta de integrar pedazos de planta a la piel humana para la producción de oxígeno. ${ }^{18}$ Ello contribuyó a que se produjera una sensación de ambigüedad frente a la posición: ¿ciencia

\footnotetext{
${ }^{18}$ La primera obra es "Pedal Power", de Christian Kuhtz (2010), y la segunda de Antal Lakner (2005).
} 
ficción o propuesta practicable? ${ }^{19}$ Esta sensación de incertidumbre fue lo que hizo que a otro entrevistado le gustara tanto de la obra:

Entrevistado: "[The Inifinity Burial Project] involucra algo práctico, una acción sobre un cuerpo en degradación en este caso para generar algo más. Lo mismo que con la otra obra que me llamó la atención, la [Dermoherba], es una simbiosis entre dos formas de vida. [...] Ambas obras [me hacen sentir] curiosidad. ¿Cómo sería tener una planta de mascota viviendo arriba tuyo?’

Pregunta: ¿Hay algún elemento particular de la obra que te llame la atención?

Entrevistado: Las dudas, en verdad. Es más la curiosidad, la curiosidad que me genera es: "¿Será viable? ¿Cómo se sentirá?" En el caso de la otra me llama la atención la idea de la muerte, más que nada, dudas que me generan." [Énfasis nuestros.]

En suma, la experiencia del público frente The Infinity Burial Project se caracterizó por curiosidad e incertidumbre, y también por un aspecto cuasi-sensorial relacionado al propio cuerpo y lo táctil. La obra evocó complejos problemas respecto a la sostenibilidad, desde la economía circular, hasta la interconectividad e interdependencia entre diferentes materias -vivas o inanimadas, humanas y otras-, y aún propulsó la imaginación sobre una práctica más sostenible de tratar la muerte. Así, la reflexión implicada en la experiencia estética se movió alrededor de la indagación sobre qué marca queremos que nuestros cuerpos dejen en la tierra, literalmente. La imaginación de cómo sería someterse a tal técnica es potenciada por el factor sensorial y acompañada por sensaciones de asombro, extrañeza e incomodidad, una combinación que anticipamos en el capítulo 3 y que ayuda explicar su alto impacto en el público de la exposición.

\section{Solar Powered Electric Chair}

El tema de la muerte y los elementos estéticos de sorpresa e incomodidad también estuvieron presentes en la obra Solar Powered Electric Chair [Silla eléctrica de energía solar], del artista y arquitecto texano David Smithson. La "silla eléctrica" tuvo una acogida muy especial por el público de Valparaíso,

\footnotetext{
${ }^{19}$ De hecho, hasta ahora The Infinity Burial Project fue aplicado al menos en una persona en los E.E.U.U., que, en situación de una enfermedad degenerativa, se acercó a Lee para candidatearse a testar el traje de entierro. Ver más (incluso un documental sobre el proceso) en: http://coeio.com/.
} 
alcanzando la mayor intensidad de discusión en las entrevistas y grupos focales. ${ }^{20}$ El siguiente extracto de una entrevista es emblemático:

"Diría que la de la silla eléctrica [fue la obra que más me llamó atención]. [...]. Porque es darle una vuelta a cómo mirar la ecología, que no necesariamente la ecología se está usando para algo bueno. O sea, como que las ideas ecológicas pueden llevar a algo muy malo también. Y creo que esa reflexión es tremendamente buena. [...] Se revuelve la guata un poco, como si realmente uno se lo imagina, aparte incluso la rueda te dice qué va pasando en cada etapa como con el voltaje que tú le das a la silla. Y es como súper sarcástica la silla, te dice como que primero se te va a secar el pelo y ya en las últimas vas a pasar cinco minutos muy difíciles, o molesto. [...].” [Énfasis nuestro.]

La sensación de sorpresa o choque fue mencionada además por muchos entrevistados al hablar sobre su primera reacción a la Solar Powered Electric Chair. Esta primera impresión se ve complementada por sensaciones de extrañeza a medida que el observador se pone a reflexionar sobre las contradicciones presentes en la obra, que además de la maqueta, contiene una guía con instrucciones que explica el funcionamiento de la silla y el paso-a-paso de sus efectos en el cuerpo de la persona electrocutada.

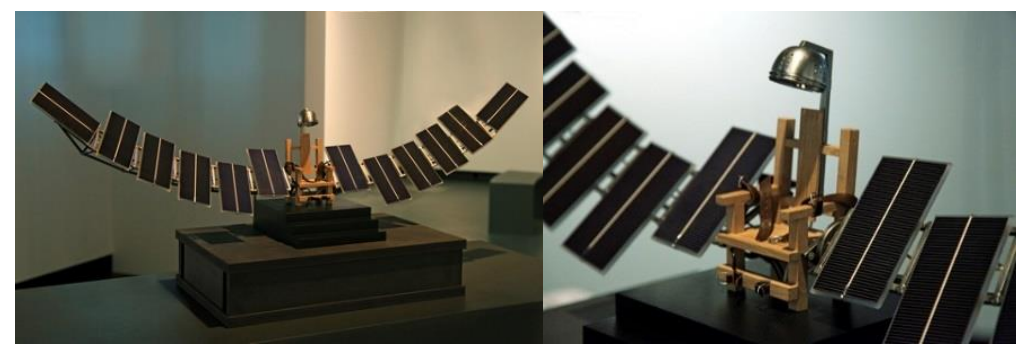

Figura 2: Solar Powered Electric Chair. Fuente: http://www.davidsmithson.net/SPEC_2.htm.

La experiencia estética con la obra está marcada por emociones de incomodidad y extrañeza conectadas a una reflexión que, por usar términos mencionados por entrevistados, "revuelve la guata", y causa "paradoja" y “conflicto". Como queda evidenciado en esta otra entrevista:

Entrevistado: "Es la sustentabilidad llevada a un nivel casi irrisorio. [...] [Me causa un] sentido de paradoja. Haber invertido tanto ingenio en una cuestión que va a terminar en muerte no tiene mayor explicación. ¡Este tipo de energías deberían ser utilizadas para vivir poh, para generar vida! [...]. Pero es

\footnotetext{
${ }^{20}$ En promedio del corpus entero de los textos transcritos, basado en el número de caracteres de los segmentos codificados, en MAXQDA.
} 
extraña esta creación. [...] Uno ve en las energías fotovoltaicas o en cualquiera de las energías renovables no convencionales y uno piensa en positivo, pero esto lo hace [pausa] te trae, te crea otro conflicto."

Pregunta: ¿Hay algo que le haga sentir esta obra?

Entrevistado: "Sorpresa primero, eh... y después, como te digo, esa sensación de paradoja constante, es como que no calza, rompe esquemas digamos." [Énfasis nuestros.]

Empezando por el objeto estético per se, un elemento de la obra que llama mucho la atención es su ejecución técnica-estética. Los detalles de la maqueta y la minuciosa descripción técnica que la acompaña confieren un aura muy realista al objeto: ${ }^{21}$

"Lo otro que me llamaba mucho la atención, si uno mira la parte de atrás, están todos los cables conectados, $y$ son cables reales, entonces, o sea, nosotros estábamos pensando "esto tiene que funcionar" [...] me llamaba la atención que está todo hecho como para que funcionase. Quizás si uno la pusiese afuera, incluso con el sol que hay, funcionaria. Son paneles reales, efectivamente funcionaría. "[Énfasis nuestro.]

El detalle realista de la obra de Smithson, al igual como en la obra de Lee, despierta una incertidumbre en el visitante, que termina preguntándose: ¿funciona?, o ¿es de hecho practicable? Para la mayoría de los y las que lo discuten, ese conflicto es solucionado por una interpretación que atribuye a la obra un carácter de "chiste", "sarcasmo" o "ironía", para mencionar términos nombrados por entrevistados. De todas maneras, tales dudas alimentan una reflexión sobre las contradicciones que pueden instaurarse en la exploración de diferentes usos para tecnologías conectadas a la sostenibilidad. Particularmente, mientras que algunos visitantes reflexionaron sobre las implicaciones de las innovaciones tecnológicas y el uso de la energía limpia, otros entrevistados se sintieron compelidos a pensar en la malversación de principios y políticas conectados al ideal de sostenibilidad. En las palabras de otro encuestado: "Me pareció impactante reflexionar respecto hacia dónde nos dirigimos con el desarrollo, dónde están las prioridades. ¿Estamos causando nuestra propia muerte? Tal vez cambiar nuestras formas de producir energía nos permita evitarlo."

\footnotetext{
${ }^{21}$ Como explicó la curadora de la muestra en una visita guiada, al vincular su obra con una crítica a la pena de muerte en su estado natal, Texas, el artista recibió como respuesta del gobernador texano de que de hecho se podría pensar en implementar el proyecto.
} 


\section{The Guide}

La obra más nombrada, comentada y discutida en la recepción de jejemplos a seguir! en Valparaíso fue The Guide [El Guía]. Concebida por el inglés radicado en Nueva York Clement Price-Thomas, la instalación es compuesta por una pila de hojas de color otoñal sobre el piso. Debajo de la pila se oculta un mecanismo que hace a las hojas subir y bajar, en un ritmo que recuerda el de la respiración humana. No sorprendentemente, la obra fue descrita por la mayoría del público como "las hojas que respiran" o "la tierra que respira", a veces también como "la tierra que vive".

Otra vez, muchos visitantes describieron su reacción frente a la obra en movimiento con las sensaciones de asombro y sorpresa. Una entrevistada llega a explicar, mediante muchas risas, que su asombro fue acompañado de la sensación de alerta y expectación frente la imaginada posibilidad de que "una persona de repente iba a salir" de las hojas.

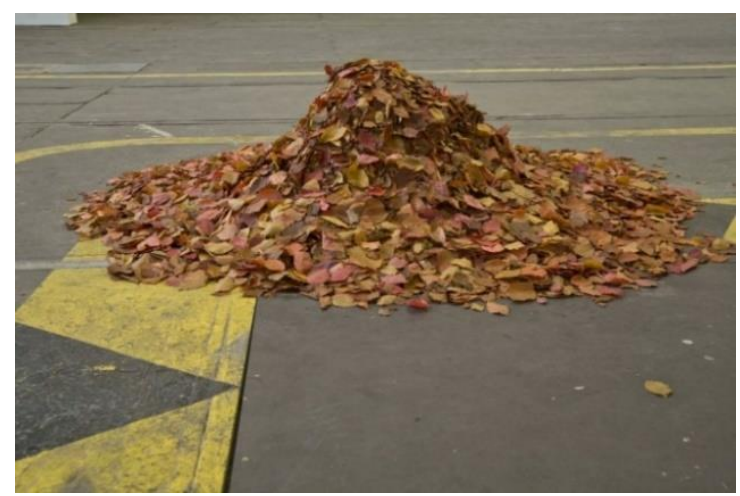

Figura 3: The Guide. Fuente: ¡ejemplos a seguir! [zne!]

Este aspecto inmediatamente lúdico de The Guide es confirmado por la especial atención que visitantes infantiles dieron a la obra, como relata esta madre:

"Lo que más me gustó fue el pasto que respiraba. Porque yo iba con mi hija que tiene cinco años y explicarle de que son seres vivos, de que los árboles que respiran o que a lo mejor pueden sentir dolor o qué sé yo, es algo que ella sólo [ve en cuentos o películas]... Entonces ver un pasto que respiraba hacía tomar consciencia de que en el fondo hay vida o hay algo ahí más allá de que puede ser algo simple que tú lo pisas y lo sacas y lo arrancas. [...] Yo la vi a ella viendo el pasto asombrada y a la vez como tomando consciencia de que hay algo ahí, de que hay algo vivo." 
El despertar de atención espontáneo por The Guide se relaciona con lo natural, pero se logra a través de un ingenio artificial. Este aspecto es también considerado por los y las visitantes: por ejemplo, un visitante adulto, muy conmovido, destaca la ejecución de la obra como causa de su emoción:

Pregunta: ¿Qué cosas le llamaron más la atención [en The Guide]?

Entrevistado: “Como está hecha, está tan bien hecha que impresiona observar que la tierra está viva, eso uno no lo ve."

Pregunta: Pero por ejemplo si Usted va a un bosque...

Entrevistado: "Puedo ir, pero que la tierra esté viva y que respire, eso es espectacular. [...] Me choca, me conmueve brutalmente. Que las artes me hagan ver algo que no había visto antes, sentir la tierra a ese nivel, así tan viva. La tierra nos sostiene, pero cuando uno dice "la tierra" piensa en otra cosa.”

Así como ese entrevistado, muchos visitantes narraron su experiencia frente la obra mencionando diferentes sensaciones y sentimientos. Lo interesante, más allá del "choque" frente al movimiento de la obra, es que las sensaciones nombradas forman una amplia gama de términos. Por un lado, varios mencionaron la sensación de paz y tranquilidad, posiblemente -como explica un encuestado-gracias al efecto kinestésico de The Guide: la obra se mueve en la forma de un pulmón y al ritmo de una respiración humana tranquila, guiando al público a cambiar su propia respiración. Ello fue interpretado como una metáfora normativa sobre la "sintonía de los seres humanos con la naturaleza".

Por otro lado, hubo quienes interpretaron las hojas otoñales como hojas muertas, connotando una amenaza a la vida de la tierra. Este grupo de visitantes percibió el movimiento de The Guide como "agonizante" o como "los últimos respiros". Como explica una entrevistada:

"Veo [el movimiento de The Guide] como representando un pulmón, el pulmón vegetal de la tierra que está muriendo porque está sobre hojas secas. Entonces es la tierra que se está muriendo por el deterioro que le hemos dado. [Y] este tipo de cosas entristece porque es el deterioro de la tierra y nuestro planeta." Como posición intermedia en el espectro vida/muerte de las diferentes interpretaciones a The Guide, el relato del participante de grupo focal abajo deja en claro una sensación de incomodidad:

"Siento [un poco incómodo] con el de las hojas que suben y bajan. Porque es como un corazón, es como si tuviera vida y lo ves que se mueven, pero tú vas al bosque y lo pisas, y lo maltratas, no lo cuidas. Y acá te lo ponen y ahí si lo cuidas. Pero porque cuando vas al bosque y eso no es lo mismo: no sé..." 
Así, la conexión con la tierra de cara a su visible respirar está, cuando no es seguida por sensaciones positivas de conexión con la naturaleza, unida a una inquieta reflexión sobre la sensibilidad de otros seres vivos y sobre la responsabilidad de los humanos para con su medioambiente. El dilema tan central en discusiones sobre DS que se instaura en la tensión entre usar y cuidar, o utilización ("desarrollo") y protección ("sostenible"), se manifiesta de manera sensible y reflexiva en la experiencia del visitante frente The Guide.

En sus distintas direcciones de significación, la experiencia estética con The Guide logra un efecto que es central en la comunicación sobre la sostenibilidad: una experiencia de la interconectividad entre humanos y el planeta, que es a la vez mediada e inmediata, reflexiva y emocional. Así, "la sensación de ver el latido de la Tierra", como la describe otro visitante en la encuesta, remite a la "sensibilidad para el padrón que conecta" (ver capítulo 3.1.) y realiza los potenciales expansivos y críticos de la experiencia estética, tan cruciales para su relación con problemas de corte planetario. La amplia gama tanto de sensaciones nombradas por el público al narrar su experiencia, así como de temas asociados con ella revela una abertura semántica vigorosa y fructífera. Resulta en diferentes significaciones, en un amplio margen de interpretación que incorpora interpretaciones incluso contradictorias, pero igualmente evidentes, noarbitrarias. Como nos recuerda Rebentisch $(2013: 55,167)$, esa alta potencialidad semántica caracteriza las ambiciones del arte contemporáneo.

\section{Green Bag Movement}

La instalación Green Bag Movement [Movimiento Bolsa Verde], del artista israelita Dodi Reifenberg, fue la segunda más mencionada por el público de la exposición en los cuestionarios. Descrita por muchos en el público como "la obra de las bolsas", "la del plástico" o "la del niño en la basura", la instalación de Reifenberg está compuesta por un área ocupada con centenas de bolsas plásticas, de diferentes colores y marcas, rodeada por bloques grises sobre los cuales se puede leer: "Tiempo promedio de producción: 2 segundos. Tiempo promedio de uso: 20 minutos. Tiempo estimado de descomposición: 1,000 años." Arriba en la pared se ve un cuadro, hecho en un mosaico a partir de fragmentos de bolsas plásticas, que representa un niño, sin camisa, que porta una bolsa bajo el brazo y camina en un basurero lleno de plástico. 


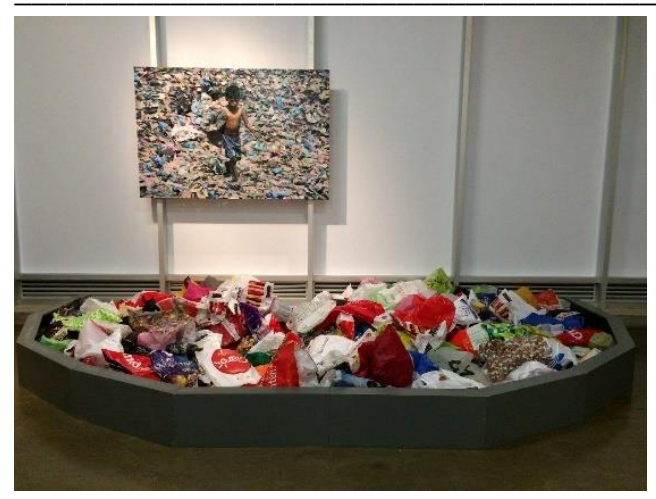

Figura 4: Greenbag Movement. Fuente: ¡ejemplos a seguir! [zne!]

Entre el público de la muestra en Valparaíso, muchos comentaron la obra describiendo emociones conectadas a tristeza. Como ejemplifica un encuestado, al justificar por qué la obra le llamó tanto la atención: "Me sorprendo del poco uso que le damos [al plástico] y no pensamos en el daño que hará desecharlas. Mil años en degradarse me pareció impresionante, me deprimió un poco". Como él, muchos visitantes de la exposición encontraron la obra muy llamativa a primera vista y, al acercase y leer la información sobre la desproporción entre los diferentes tiempos respecto producción, uso y descomposición del plástico, experimentaron primero asombro, luego malestar. Para muchos receptores, la imagen del niño además les causó una sensación de angustia o sentimiento de desesperanza.

Según Thomsen (2015: 4), investigaciones empíricas demuestran que la respuesta emocional a imágenes es más significativa cuando las mismas representan a un ser humano. Además, recuenta que el "sublime tóxico", como tensión entre la belleza estética y la fealdad del paisaje contaminado, tiene el potencial de cautivar al público, y deja una conflictiva sensación de asombro y fascinación (Thomsen, 2015: 3). Esa paradoja está también muy presente en la experiencia con otras obras de jejemplos a seguir! que trabajan con el tema de la basura y la contaminación, ${ }^{22}$ pero solo en el caso de Reifenberg va acompañada de la presencia del ser humano individual, combinación que puede explicar el impacto particular de esta obra.

Capturadas por esas tensiones, varias personas en el público de la muestra comentaron que la obra de Reifenberg les hizo pensar y reflexionar. Como queda ejemplificado en un comentario en la encuesta: "a

\footnotetext{
${ }^{22}$ Entre otras obras en esta temática en jejemplos a seguir! destacan la famosa intervención landart en un territorio explorado por minería Spiral Jetty, de Robert Smithson, la serie de cuadros sobre plástico prensado Waste, de Till Leeser, y la serie de fotografías hechas por Xing Danwen en un basurero de desechos electrónicos internacionales en Guangdong, China. Ver en: http://www.z-n-e.info/?root=2ysub=0ykat=0yid=0ylang=en. Acceso: 18 Jun 2018.
} 
pesar de que convivimos y contribuimos a generar basura día a día, verlo expresado tan literal y gráficamente da un remezón de consciencia.” El potencial reflexivo de la obra radica en su relación con una experiencia muy cotidiana, trayendo a la luz su profunda insostenibilidad. Muchos visitantes, a propósito de la obra, llegaron a reflexionar sobre temas como (sobre)consumo, exceso, agotamiento de recursos naturales, y la relación entre provecho y daño. ${ }^{23}$ Por otro lado, muchos entrevistados asociaron Green Bag Movement directamente a dos tipos de solución o posibilidades de acción para más sostenibilidad, a saber: generar consciencia, por un lado, y la reutilización o reciclaje, por otro.

\section{Sostenibilidad: (des)entendimientos desde el arte}

La mención del concepto "sostenibilidad" en las entrevistas con visitantes de la exposición evidenció que éste evoca desentendimientos: la única pregunta de la entrevista que no fue viable fue justo aquella que intentaba indagar en el aprendizaje de las y los visitantes sobre sostenibilidad. A pesar de simplificarla después de los pre-tests, ${ }^{24}$ la pregunta en general recibió respuestas negativas, es decir, las personas afirmaban no haber aprendido nada nuevo. La pregunta, en cualquiera de sus formatos, asume que las personas tienen conocimientos previos sobre el concepto de sostenibilidad, cuando en realidad se trata de un concepto ampliamente utilizado, pero muy poco discutido.

A pesar de ello, participantes del estudio mencionaron diferentes aspectos conectados a cuestiones centrales en la discusión sobre DS, como derroche de recursos, degradación, contaminación, necesidad de “cuidado con el planeta” y futuras generaciones. Para entender cuáles temas surgieron y cuáles no, debemos considerar los nexos entre tres esferas: los temas presentes en las discusiones internacionales y locales sobre sostenibilidad, los temas presentes en la exposición, y los temas resaltados por su público local. Como vimos en la segunda sección del presente artículo, basura, agricultura, agua, patrimonio y desarrollo urbano han sido los principales aspectos recogidos por las organizaciones que intentan enfrentar las problemáticas socioambientales que afectan Valparaíso y comunas vecinas. Pero solo los dos primeros

\footnotetext{
${ }^{23}$ Como reflexionó un encuestado: “Creo que [la obra] refleja lo absurdo de los sistemas de consumo actuales. Potenciando industrias de producción absolutamente innecesarias en su relación impacto-usabilidad."

${ }^{24}$ Originalmente, la pregunta estaba enunciada de la siguiente forma: "La exposición aborda diversos temas conectados con sostenibilidad. ¿Hubo algún motivo o tema en la exposición que, antes de su visita, Ud. no habría asociado con la temática de sostenibilidad?". Producto de los recurrentes desentendimientos, se reformuló la segunda frase en términos más simples: “¿considera que aprendió algo nuevo con la visita a la exposición?”.
} 
temas resonaron en el público de jejemplos a seguir!, como ejemplifica la gran atención dada a la obra sobre plásticos de Dodi Reifenberg y a la obra sobre la pérdida de diversidad del trigo de Ursula SchulzDornburg. Los demás temas, aunque abordados en la exposición por diferentes obras, fueron poco comentados por los visitantes. ${ }^{25}$ La explicación de esa laguna puede buscarse en dos direcciones: la de la predisposición del público porteño, o la del arte.

Por un lado, podemos pensar que esos temas son pautados por $-\mathrm{y}$ relegados a - específicas organizaciones y, así, se observa una atomización de la discusión sobre sostenibilidad en lugar de una discusión abiertamente pública, que no tiene suficiente refuerzo en los medios de comunicación masiva y en la esfera política. Por tanto, asuntos tan urgentes como la escasez de agua no poseen una resonancia acorde ni entre la población chilena y de la V región en general (ver datos de encuestas citados en capítulo 2) ni entre las y los visitantes a la exposición. La poca atención al grave problema del agua -notable también en la escasa asistencia de público al respectivo bloque de conversatorios- además es reforzada por la invisibilización del problema en la urbe, una vez que lo mismo es cotidianamente visible en la experiencia de la población de Petorca.

Por otro lado, la potencialidad estética de determinadas obras también nos ayuda a explicar la (falta de) resonancia de determinados temas en la recepción de jejemplos a seguir!. Más allá de detenerse en el hecho de que algunos de los temas menos discutidos corresponden a obras que fueron menos destacadas estéticamente, p. ej. basadas en grabaciones de video y explicaciones escritas, vale analizar la potencialidad específica de aquellas obras que despertaron mayor atención y propulsaron mayor discusión. Como vimos en la sección anterior, determinados elementos estéticos fueron fundamentales para captar la atención del público, activar su sensibilidad y apalancar su reflexión.

Entre ellos, destaca la creación de ambigüedad e incertidumbre, factores que instigaron curiosidad y/o extrañeza, como fue muy bien logrado por las obras The Infinity Burial Project, Solar Powered Electric Chair y The Guide. Además, cada obra discutida fue notable en lograr la evocación de lo somático en el observador. Eso ocurrió a través del surgimiento de empatía con la representación del niño en el basurero

\footnotetext{
${ }^{25}$ Las pocas menciones se limitan a la instalación sobre un filtro de agua casero, del Colectivo Zwischenbericht, que obtuve algunas menciones en los cuestionarios y en pocas entrevistas, así como la obra Halong VI, de Dionísio Ganzález, que toca los temas patrimonio, turismo y arquitectura, en su representación ficticia de un proyecto urbano-fluvial en Vietnam.
} 
en Greenbag Project, a través de la sensibilidad virtual de la imaginación de someter el propio cuerpo a la técnica propuesta por The Infinity Burial Project, en la lectura de la gráfica descripción de lo que ocurre con un cuerpo electrocutado en Solar Powered Electric Chair, y en la sensibilidad del efecto kinestésico de las hojas que respiran en The Guide. Más allá, en Infinity Burial Project, pero especialmente en The Guide, la apertura de significación ofrecida por las obras condujo a una amplia gama de asociaciones y pensamientos entre el público, que las interpretó de diferentes maneras, pasando por diversos temas. Otra característica estética, aunque más de contenido que de forma, en las cuatro, pero en especial en Infinity Burial y The Guide, es la transversalidad de su abordaje temático. Esta característica es interesante no solamente en el sentido de que la atención prestada a cada obra se potencia cuando sus variados temas despiertan diferentes intereses en diferentes destinatarios, sino también en su función de condensar distintos aspectos en los complejos problemas representados. Así, la capacidad de su estética para conectar procesos distantes y dispares, generando reflexión sobre ellos, corresponde a lo que es quizás el principal desafío en la comunicación sobre la (in)sostenibilidad. Aunque esa capacidad, dada la especificidad temática de las obras mencionadas, no haya podido extenderse a las dimensiones de justicia y equidad social tan centrales para el concepto DS, cabe enfatizar la trascendencia del mecanismo que le subyace.

Finalmente, queda por discutir en qué grado y de qué manera la reflexión surgida en la experiencia estética en la exposición se tradujo a ideas de acciones sostenibles. Algunas obras en jejemplos a seguir!, como en el emblemático caso de The Infinity Burial Project, demuestran el potencial imaginativo que el arte puede alcanzar cuando proponen nuevas soluciones a problemas socio-ecológicos. De hecho, tal obra fue mencionada por cuatro visitantes frente a una pregunta de la entrevista sobre qué ejemplos a seguir ellos se llevarían de la exposición. Entretanto, con esta y pocas otras excepciones, la pregunta no fue tan fructífera. Solo dos tipos de posibilidades de acción hacia más sostenibilidad fueron vislumbrados por el público entrevistado en general: reciclar y tomar (o generar) consciencia.

La preeminencia del tema reciclaje tiene una base en la opinión pública chilena en general, y en las discusiones públicas locales: Valparaíso ha sido, durante años, una comuna donde la basura es un problema notorio, hecho que ha dado lugar a varias campañas. En el contexto de la muestra, uno de los eventos de diálogo con mayor cantidad de público tuvo como exponente al encargado de la Dirección de Aseo Municipal y al Alcalde de la ciudad, y la conversación abordó el tratamiento de residuos e instó a 
hacer del reciclaje una práctica ciudadana presente en cada hogar. Esto es coherente con un relato construido a nivel nacional por el gobierno central, que si bien no ha desarrollado acciones sistemáticas pro-reciclaje (puesto que se concentran mayoritariamente en Santiago), sí ve con buenos ojos a quienes articulan este tipo de prácticas. Siguiendo aquello, distintos actores se han incorporado en este esquema (como los Municipios, Valparaíso entre ellos) pero, sobre todo, se observa un empresariado que, sin nunca disputar el concepto de lo sostenible, proyecta una imagen amigable a través de campañas de reciclaje y venta de eco-bolsas para el transporte de los productos comprados en sus sucursales, hecho que sigue llamando a consumir y en ningún caso a reducir. De hecho, mientras la reutilización de materias fue muy discutida por el público y asociada a diferentes obras en la muestra, la reducción del consumo casi no fue mencionada. $^{26}$

Acerca del énfasis en la necesidad de tomar o generar consciencia, mencionada 30 veces en el estudio, es interesante percibir que la misma, en gran medida, es articulada sin ser acoplada a acciones (más allá de reciclar o no desperdiciar) ni a consecuencias concretas. Aunque varios entrevistados expresaran la idea que la concientización ambiental es "un punto de partida" para el DS, lo hicieron de manera vaga. Además, menciones explicitas al ámbito político, o a actores del campo político, como autoridades gubernamentales o movimientos sociales, fueron encontradas muy pocas veces en el material recolectado.

Estos aspectos indican una importante ausencia en la recepción de jejemplos a seguir!: la falta de conexión con la dimensión institucional, política y conflictiva del DS. Ello es coherente con la apropiación superficial de la sostenibilidad por el sector empresarial en Chile y en el despliegue de la institucionalidad en discusiones sobre el tema. La tendencia de vaciamiento político también fue criticada por algunos participantes en los grupos focales, los que, sin embargo, tampoco lograron articular la conexión entre DS y procesos políticos. Complementariamente, ese diagnóstico puede ser también explicado a través de la muestra: La exposición, quizás por su enfoque en ejemplos a seguir de varias partes del mundo, no logró transportar la dimensión política-territorial al público local chileno. Aunque la obra titular de la exposición, Under Discussion, tematice justamente los intereses y discusiones políticos por detrás de la demarcación de un territorio, irónicamente esta obra, así como esta dimensión temática pasó desapercibida por la gran mayoría del público.

\footnotetext{
${ }^{26}$ Apenas un participante del estudio mencionó la posibilidad de “dejar de consumir plástico" y otras dos "no consumir carne”, mientras reciclaje o reutilización fueron mencionadas 40 veces.
} 


\section{Consideraciones finales}

En este artículo, quisimos contribuir a la exploración empírica del potencial del arte en comunicaciones sobre sostenibilidad. Tratándose una exposición de arte contemporáneo que pretende abordar la pluralidad internacional en el campo temático de la sostenibilidad, el impacto de jejemplos a seguir! es susceptible a la recepción de su público local. Como vimos en la teoría, el arte tiene la potencialidad de activar la sensibilidad y generar reflexión en su experiencia estética, posiblemente fertilizando la idea de un futuro sostenible - pero esa potencialidad, según nuestro estudio, se realizó de forma moderada.

En el caso de Valparaíso, observamos que algunas obras despiertan una experiencia estética de profundo impacto en el público, gracias a componentes sensoriales y polisemias y ambigüedades estéticas. Al mismo tiempo notamos que otras obras $-\mathrm{y}$ otros temas- no recibieron tanta atención: en general, las dimensiones política y territorial del DS, presente en algunas obras de la exposición, no resonaron entre su tan numeroso público. Así, notamos que los logros de la experiencia estética vislumbradas en la literatura de hecho pueden ocurrir, como bien mostraron los casos de la recepción de las cuatro obras discutidas en más detalle, pero no se pueden dar por hecho. Su potencialidad es, antes de todo, una posibilidad. En el contexto de una forma de comunicación que propone tocar el tema de la sostenibilidad, observamos en el caso analizado que el arte no puede llenar vacíos en la discusión pública; pero sí puede apuntar a tales vacíos. Más importante aún, el arte puede expandir y reestructurar temas ya presentes en discusiones públicas: puede problematizarlos más allá de lo conocido y conectarlos a otras posibilidades y niveles (muchas veces somáticos) de entendimiento, produciendo la posibilidad de imaginar y reflexionar sobre posibles nuevos caminos más allá de las fronteras de la experiencia factual cotidiana.

\section{Referencias bibliográficas}

Adorno, T. W. (1970). Ästhetische Theorie. Frankfurt am Main, Alemania: Suhrkamp.

Arriagada, E. (1992). Empresas, empresarios y la Cumbre de la Tierra. Ambiente y Desarrollo, VIII(2), 52-57.

Barloewen, C., y Rivera, M. (2014). Introducción. En C. Barloewen, M. Rivera y K. Töpfer (Ed.), Desarrollo sostenible en una modernidad plural. Perspectivas latinoamericanas (pp.15-49). Quito, Ecuador: Abya-Yala.

Barnett, J. T. (2018). Politics of Edibility: Reconceptualizing Ecological Relationality. Environmental Communication 12 (2), 218-231 
Biblioteca del Congreso Nacional. (4 de Mayo de 2017).Seminario: construyendo ciudades sostenibles e inclusivas en Chile. Recuperado de Biblioteca del Congreso Nacional: https://www.bcn.cl/noticias/seminario-construyendociudades-sostenibles-e-inclusivas-en-chile

Biblioteca del Congreso Nacional. (1994). Historia de la Ley 19.300: Aprueba Ley sobre bases generales del medio ambiente. Santiago de Chile.

Biblioteca del Congreso Nacional. (2010). Historia de la Ley no. 20.417: crea el Ministerio, el Servicio de Evaluación Ambiental y la Superintendencia de Medio Ambiente. Santiago de Chile.

Bubner, R. (1989). Ästhetische Erfahrung. Frankfurt am Main, Alemania: Suhrkamp.

Camus, P., y Hajek, E. (1998). La historia ambiental de Chile entre 1964 y 1994. En P. Camus, y E. Hajek. Historia ambiental de Chile (pp. 15-50). Santiago de Chile: Andros Impresores.

Chile Desarrollo Sustentable. (11 de febrero de 2017). Acuerdos internacionales: información asociada. Recuperado de Chile Desarrollo Sustentable: http://www.chiledesarrollosustentable.cl/desarrollo-sostenible/ministerio-demedio-ambiente/informacion-asociada/acuerdos-internacionales/

Clammer, J. (2014). Towards a sociology and anthropology from art. London, Inglaterra, y New York, E.E.U.U.: Routledge.

Consejo Nacional de la Infancia. (2017). Informe de resultados Regional Yo Opino, es mi derecho 2017, Valparaíso. Santiago de Chile: s/e.

Corvalán, M., Pérez-Cueto, C., y Fierro, P. (22 de abril de 2015). Cómo contribuyen las empresas chilenas a la sustentabilidad. La Tercera.

Cuenca, L. (junio de 2011). La evolución de las luchas medioambientales en Chile. Recuperado de Observatorio Latinoamericano de Conflictos Ambientales: http://www.olca.cl/oca/chile/mineras/mineras074.htm

Demos, T. J. (2016). Decolonizing nature: Contemporary art and the politics of ecology. Berlin, Alemania: Sternberg Press.

DESUC (2018). Informe final: Encuesta nacional de medio ambiente 2018. Santiago de Chile: s/e.

Eco, U. (1973). Das offene Kunstwerk. Frankfurt am Main, Alemania: Suhrkamp.

Empresa Portuaria de Valparaíso. (s/f de s/f de 2016). Empresa Portuaria de Valparaíso. Recuperado el 6 de Marzo de 2018, de Empresa Portuaria de Valparaíso: https://www.puertovalparaiso.cl/img/media/1467925787_Plansusten2016.pdf

Gonzalez, J. Z., Castro Romero, M., y Marín Toro, A. (2013). Determinación de necesidades de investigación en turismo. El Caso del Centro de Investigación en Turismo y Patrimonio de la Región de Valparaíso, Chile. Estudios y perspectivas en turismo, 22(5), 926-952.

Green, M. C., y Brock, T. C. (2000). The role of transportation in the persuasiveness of public narratives. Journal of Personality and Social Psychology 79(5), 701-721.

Grober, U. (2012). Sustainability. A cultural history. Totnes, Inglaterra: Green Books. 
Hamker, A. (2003). Emotion und ästhetische Erfahrung: Zur Rezeptionästhetik der Video-Installationen Buried Secrets von Bill Viola. Münster, Alemania: Waxmann.

Hansen, A. y Cox, R. (2015). The Routledge Handbook of Environment and Communication. London, Inglaterra, y New York, E.E.U.U.: Routledge.

Instituto Nacional de Derechos Humanos. (18 de agosto de 2016). INDH presenta nueva versión del Mapa de Conflictos Socioambientales en Chile. Recuperado de Instituto Nacional de Derechos Humanos: https://www.indh.cl/indh-presenta-nueva-version-del-mapa-de-conflictos-socioambientales-en-chile/

Kagan, S., y Kirchberg, V. (Ed.) (2008). Sustainability: a new frontier for the arts and cultures. Frankfurt am Main, Alemania: VAS.

Kagan, S. (2013). Art and Sustainability: Connecting Patterns for a Culture of Complexity. Bielefeld, Alemania: transcript Verlag.

Knebush, J. (2008). Art and Climate (Change) Perception: outline of a phenomenology of climate. En S. Kagan, y V. Kirchberg (Ed.). Sustainability: a new frontier for the arts and cultures (pp. 242-262). Frankfurt am Main, Alemania: VAS.

Kronfeld-Goharani, U. (2015). The discursive constitution of ocean sustainability. Advances in Applied Sociology 5: 206-330.

Leyda, J., Loock, K., Starre, A., Barbosa, T. P., y Rivera, M.. (2016). The Dystopian Impulse of Contemporary CliFi: Lessons and Questions from a Joint Workshop of the IASS and the JFKI (FU Berlin). IASS Working paper. Potsdam, Alemania: IASS. Recuperado de: https://www.iasspotsdam.de/sites/default/files/files/wp_nov_2016_the_dystopian_impulse_of_contemporary_cli-fi.pdf.

Maquet, J. (1988). The aesthetic experience: An anthropologist looks at the visual arts. London, Inglaterra: Yale University Press.

Marcuse, H. (1969). An Essay on Liberation. Boston, E.E.U.U.: Beacon Press.

Meadows, D.H., Meadows, D.L., Randers, J., Behrens, W. W. (1972). The limits to growth. A report the Club of Rome's project on the predicament of mankind. New York: Universe Books.

Molina, R. (20 de julio de 2012). Sustentabilidad: el gran ausente en el debate sobre la Ley de Pesca. Centro de Investigación Periodística. Recuperado de Centro de Investigación Periodística: https://ciperchile.cl/2012/07/20/sustentabilidad-el-gran-ausente-en-el-debate-sobre-la-ley-de-pesca/

Moreno, E. L., Clos, J. y Ki-moon, B. (2016). Urbanization and development: Emerging futures: world cities report 2016. World cities report: Vol. 2016. Nairobi, Kenia: UN Habitat.

Naciones Unidas (1987). Informe de la Comisión Mundial sobre el Medio Ambiente y el Desarrollo: Nuestro futuro común. A/42/427. Nueva $\quad$ York. Recuperado de: http://www.ecominga.uqam.ca/PDF/BIBLIOGRAPHIE/GUIDE_LECTURE_1/CMMAD-Informe-ComisionBrundtland-sobre-Medio-Ambiente-Desarrollo.pdf 
Observatorio de Sostenibilidad. (2016). Primer informe: Sostenibilidad de Chile y sus regiones 2015. Santiago de Chile: Facultad de Economía y Negocios, Universidad de Chile.

Pérez Carreño, F. (1999). Nelson Goodman. En V. Bozal (Ed.). Historia de las ideas estéticas y de las teorías artísticas contemporáneas (pp.106-101). Madrid, España: Visor, 1999.

Plan Cerro. (15 de Mayo de 2017). Plan Cerro. Recuperado de Plan Cerro: http://www.plancerro.cl/singlepost/2017/05/15/Plan-C\%C2\%BA-en-seminario-organizado-por-la-Biblioteca-del-Congreso-Nacional

Rebentisch, J. (2013). Theorien der Gegenwartskunst: Zur Einführung. Hamburg, Alemania: Junius.

Rivera, M. (2015). Wie viel Entpolitisierung vertragen die SDGs? Ein kritischer Blick auf die Entstehung der Agenda 2030. IASS Working Paper. Potsdam, Alemania: IASS.

Robin, L. (2018). From the environment to the Anthropocene: A history of changing expertise 1948-2018. En F. Trentmann, A.B. Sum, y M. Rivera (Ed.): Work in progress. Economy and environment in the hands of experts (p. 183-203). Munich, Alemania: oekom.

Sabatini, F. (1997). Conflictos ambientales y desarrollo sustentable de las regiones urbanas. EURE, 23(68), 77-91.

Salama, S., y Aboukoura, K. (2018). The Role of Emotions in Climate Change Communication. En: W. Leal Filho, E. Manolas, A.M. Azul, U.M. Azeiteiro, Y H. McGhie. Handbook of Climate Change Communication: Vol. 1. Theory of Climate Change Communication. (pp.137-150). Springer International Publishing.

Thomsen, D. C. (2015). Seeing is questioning: prompting sustainability discourses through an evocative visual agenda. Ecology and Society 20(4):9.

Tsing, A. L. (2015). The Mushroom at the end of the world. On the possibility of life in capitalist ruins. Princeton, E.E.U.U.: Princeton University Press.

Valcarcel, M. (2006). Génesis y evolución del concepto y enfoques sobre el Desarrollo. Departamento de Ciencias Sociales, Pontificia Universidad Católica del Perú, 2-41.

Zschocke, N. (2006). Der irritierte Blick: Kunstrezeption und Aufmerksamkeit. München, Alemania: Wilhelm Fink. 